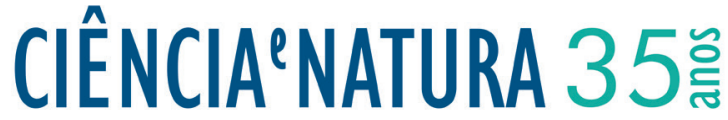

\section{A Climatologia Geográfica no Brasil e na Itália}

\author{
The Geographical Climatology in Brazil and Italy
}

\author{
João Afonso Zavattini*1 \\ ${ }^{1}$ Professor do Programa de Pós-graduação em Geografia do Instituto de Geociências e Ciências Exatas, \\ Universidade Estadual Paulista Júlio de Mesquita Filho, Rio Claro - São Paulo, Brasil
}

\begin{abstract}
Resumo
Neste artigo o autor procura justificar o interesse pelo tema da pesquisa que desenvolveu na Universidade de Turim (Itália) e os motivos que o levaram a comparar as influências exercidas por Mario Pinna - na Climatologia Geográfica Italiana - e por Carlos Augusto de Figueiredo Monteiro - na Climatologia Geográfica Brasileira. Com esse intuito faz o resgate dos princípios norteadores dessa área do conhecimento, destacando a contribuição oferecida pelos franceses Maximilien Sorre e Pierre Pédelaborde que, de um modo particular, propuseram novas abordagens do tempo e do clima e influenciaram os estudos climáticos conduzidos por geógrafos. Por consequência, os estudos geográficos do clima passaram a diferenciar-se, desde então, daqueles conduzidos por meteorologistas e demais pesquisadores em climatologia. O autor, além de revelar os principais resultados colhidos no extenso levantamento bibliográfico que efetuou, englobando livros e periódicos científicos italianos, os contrapõe aos trabalhos produzidos no Brasil e, nas suas considerações finais, argumenta sobre a necessidade de um caráter genético à classificação dos climas da Terra.
\end{abstract}

Palavras-chave: Climatologia Geográfica, Brasil, Itália, França, Tempo, Clima, Geografia, Meteorologia, Classificação Climática, Pinna, Monteiro, Sorre, Pédelaborde.

\begin{abstract}
In this article the author attempts to justify his interest in the topic of his research project developed at the University of Turin (Italy) and the reasons which led him to compare, in his study, the influences of Mario Pinna on Italian Geographical Climatology and of Carlos Augusto de Figueiredo Monteiro on Brazilian Geographical Climatology. Therefore, he exposes the guiding principles of this area of knowledge, highlighting the contributions of frenchmen Maximilien Sorre and Pierre Pédelaborde, which in particular, proposed new approaches to weather and climate studies and influenced the researches conducted, in this area, by geographers. Consequently, since them, the geographical studies of climate began to develope differently than those carried out by meteorologists and other researchers of climatology. The author, in addition to revealing the main results of his extensive bibliographic survey of Italian scientific books and journals, contrasts them to works produced in Brazil and, in his final considerations, ponders about the need to impart a genetic quality to the classification of Earth's climates.
\end{abstract}

Keywords: Geographical Climatology, Brazil, Italy, France, Weather, Climate, Geography, Meteorology, Climate Classification, Pinna, Monteiro, Sorre, Pédelaborde.

* jazavattini@hotmail.com

Recebido: 19/03/2014 Aceito: 19/03/2014 


\section{Introdução}

\subsection{Enquadrando o tema: uma explicação necessária.}

$\mathrm{M}$ inha formação em Geografia, ligada ao pensamento francês de então, foi complementada com a especialização em Climatologia, fortemente embasada na ampla contribuição que Monteiro ofereceu ao Brasil e nos ensinamentos de Sorre (1955) e Pedélaborde $(1957 ; 1970)$ sobre o clima ${ }^{1}$. Por tais motivos, trabalhando com dados climáticos exclusivamente brasileiros, produzi - preferencialmente - na ótica da "análise rítmica" (MONTEIRO, 1971). Só recentemente é que meus interesses se voltaram, também, para a Itália, em particular à influência que expoentes da Geografia exerceram nos estudos do clima lá desenvolvidos².

Foi nesse escopo que cogitei a realização de um estágio de pós-doutorado naquele país e me aconselhei com Vincent Dubreuil, da Association Internationale de Climatologie (AIC) e professor da Universidade de Rennes (França), que me sugeriu entrar em contato com Simona Fratianni, sua colega de AIC e assistente de Augusto Biancotti, ambos docentes da Universidade de Turim (Itália). Os contatos com a Professora Fratianni foram promissores. Estimulado eu redigiria, ao longo do primeiro trimestre do ano de 2005, uma proposta de trabalho com vista à obtenção de uma bolsa de estudos, a seguir submetida ao Conselho Nacional de Desenvolvimento Científico e Tecnológico (CNPq). Nesse ínterim, enquanto aguardava o resultado da submissão, preparei um trabalho para o colóquio da AIC (Gênova, setembro de 2005), contendo resultados de minha tese de livredocência (ZAVATTINI, 2005).

Na formulação daquela proposta de trabalho, a parte teórica da pesquisa previa o levantamento de estudos do clima feitos na Itália, em período a ser definido a posteriori com o Professor Biancotti. Já a parte prática, fundamentada na obra "Macaronesia: uomo, ambiente, spazio e território nelle isole dell' Atlantico orientale" (BIANCOTTI, 2001), contemplaria a "análise rítmica", cujos gráficos seriam elaborados a partir das variações diárias e horárias dos elementos do clima, medidas em ilhas desses arquipélagos e associadas à circulação atmosférica atuante no Atlântico Norte-oriental ${ }^{3}$.

1 Zavatini $(1983 ; 1990 ; 1992 ; 1996 ; 1998 ; 2000)$, Zavattini $(2000 ; 2001$; 2002; 2003; 2004; 2005; 2009), Fratianni; Zavattini (2006; 2007; 2009), Zavattini; Boin (2013), além de outros trabalhos.

2 Após o lançamento do livro "Estudos do Clima no Brasil" (ZAVATTINI, 2004).

3 “Dalle acque dei quadrante orientali dell' Atlantico emergono cinque arcipelaghi. A partire da nord verso sud: le Azzorre, Madeira, le Selvagge, le Canarie e Capo Verde, una trentina di piccole isole in tutto, con il corteggio di un numero imprecisato di scogli. Le più minuscole, le due Selvagge, sono deserte, le altre ospitano popolazioni piuttosto dense, distribuite in modo irregolare. L'insieme di queste terre è conosciuto con il nome di Macaronesia, il paese della felicità, l'antica Atlantide narrata da Platone nel Timeo e nel Crizia, l'Iperborea della legenda nordica, la terra di Mu e di Mud evocata dai Maya sull'altra riva dell'oceano." (BIANCOTTI, 2001;p.7)
Ao findar o ano de 2005 eu seria informado, quase que ao mesmo tempo, da morte precoce de Augusto Biancotti $\left({ }^{*} 15 / 7 / 1946 ;+25 / 9 / 2005\right)$ e da concessão da bolsa pelo CNPq. Procurei lidar, da maneira que me foi possível, com esses dois fatos. Assim, após os arranjos necessários, especialmente na parte prática do projeto de pesquisa, a Profa. Dra. Simona Fratianni incumbiu-se da supervisão ${ }^{4}$. Pude, então, realizar o estágio de pós-doutorado na Universidade de Turim, de abril de 2006 a março de 2007. Para lá eu retornaria num segundo estágio, de dezembro de 2010 a março de 2011, graças à bolsa oferecida pela Pró-reitoria de Pós-graduação da UNESP, quando pude completar o levantamento bibliográfico outrora iniciado. Dessa maneira, cobrindo mais de meio século de produção científica (1950 a 2010), reuni várias obras completas e inúmeros artigos publicados em diversos periódicos italianos, com destaque para os seguintes: "Bollettino della Società Geografica Italiana", "Rivista Geografica Italiana", revista "Cultura e Scuola", revista "L'Universo", "Memorie della Società Geografica Italiana", "Rivista Geografia Fisica e Dinamica Quaternaria", "Rivista di Meteorologia Aeronautica", além de outros.

\section{$2 \mathrm{Um}$ pouco de história da climatologia geográfica}

\subsection{Remontando e compreendendo: a influên- cia francesa e a originalidade brasileira.}

Para uma melhor compreensão da Climatologia Geográfica e de sua importância na atualidade é preciso remontar à década de trinta do século XX e reconstituir, mesmo que de forma breve, a influência francesa nos cursos superiores de Geografia e, por consequência, nos estudos do clima no Brasil. Entre 1934 e 1948, a participação de mestres estrangeiros, principalmente franceses, no processo de implantação dos primeiros cursos de Geografia no Brasil foi fundamental. Segundo Monteiro (1980; p. 10):

[...] A partir da criação da Universidade de São Paulo e especialmente de sua Faculdade de Filosofia, Ciências e Letras, logo seguida pela do Rio de Janeiro e pela fundação da AGB, sob a égide de Pierre Deffontaines, iniciou-se o processo ${ }^{5}$.

\footnotetext{
4 As "análises rítmicas" não seriam mais praticadas com dados da Macaronesia e, sim, com dados climáticos do norte da Itália, interligados à produção vitivinícola no terroir do Barolo e à prática dos esportes de inverno nos Alpes Piemonteses.

5 Monteiro (1980, p. 11) explica que "[...] Após a fase de instalação dos cursos de Geografia e História tanto em São Paulo quanto no Rio de Janeiro por Deffontaines, a cooperação cultural francesa colocaria na primeira, 1935, Pierre Monbeig, geógrafo jovem em busca do seu 'doctorat' que, assumindo a orientação da então cadeira de Geografia, passou ativa e eficazmente à formação dos Geógrafos na USP. $[\ldots]^{\prime \prime}$
} 
Porém, de 1948 a 1956, houve o retorno dos mestres estrangeiros a seus países de origem e, também, o envio sistemático de geógrafos bolsistas à França e aos Estados Unidos (MONTEIRO, 1980) que, por sua vez, ao regressarem ao Brasil, influenciariam - até os nossos dias - os estudos aqui praticados. Exemplo dessa forte influência, presente até os dias de hoje nos estudos do clima, foi a divulgação em São Paulo, por parte de Ary França, das idéias do geógrafo francês Maximilien Sorre. De acordo com Monteiro (1980, p. 16):

[...] Sobretudo pelos bolsistas retornados de França houve difusão de novas idéias, revelação de novos geógrafos franceses. Foi o caso da difusão das idéias de SORRE, em São Paulo, por Ari França, no início desse período (influência marcante e sensível ainda hoje) e de Tricart, no Rio de Janeiro, por vários bolsistas de volta de Estrasburgo, ao longo de todo esse período.

Foi quando veio a público a crítica de Sorre ao emprego, insensato, da média aritmética em climatologia pois, afinal, trata-se de um cálculo estatístico desvinculado da ação e interação do clima sobre e com os seres vivos.

Foi, também, quando se tomou conhecimento do escopo das idéias originais de Sorre a respeito da classificação biológica dos climas. E, em especial, do seu conceito de clima: "On appelle climat la série des états de l'atmosphère au-dessus d'un lie dans leur succession habituelle" (SORRE, 1943, p.13-14), verdadeiro divisor de águas dos estudos do clima no Brasil ${ }^{6}$.

Esse conceito que foi abordado, pioneiramente, na tese de doutorado de Ary França, intitulada "Estudo sôbre o clima da bacia de São Paulo", defendida em 1945 e publicada em 1946, na qual incorpa os dados da dinâmica atmosférica, à partir da contribuição de Adalberto Serra e Leandro Ratisbonna, meteorologistas brasileiros hoje praticamente relegados ao ostracismo ${ }^{7}$.

Sobre os tipos de tempo que atuam na cidade de São Paulo, contrapondo-se a Sampaio Ferraz (1942), Ary França (1946, p. 53) afirma:

6 "[...] Para o geógrafo, as combinações dos elementos do clima devem ser encaradas apenas em face das condições da superfície de um lugar, as quais modificam os característicos e comportamento das massas de ar. São essas condições que permitem a ocorrência de tipos de tempo, na sua 'sucessão habitual', que, de acôrdo com Sorre, constituem a 'ambiência atmosférica' definida como clima (LVII). [...]" (FRANÇA, 1946, p. 31).

7 “[...] No estudo do clima da cidade de São Paulo, visando principalmente a caracterização dos tipos de tempo e a sua sucessão no decorrer do ano, interessa conhecer os característicos e posições relativas de três das grandes massas de ar do hemisfério sul, as quais, estendendo-se a partir das respectivas regiões de origem até e além da região de S. Paulo, produzem todas as combinações típicas do nosso clima. São elas a Tropical Atlântica (Ta), a Equatorial Continental $(\mathrm{Ec})$ e a Polar Atlântica $(\mathrm{Pa})$, cujas posições médias e em relação à cidade de S. Paulo aparecem na figura n.. ${ }^{\circ}$ 11, extraída do excelente trabalho dos mestres da nova meteorologia sul-americana, Adalberto Serra e Leandro Ratisbonna, "As massas de ar da América do Sul" (LII). [...]" (FRANÇA, 1946, p. 32).
[...] Em um estudo dedicado aos climas do Estado de S. Paulo, Sampaio Ferraz (XLV, pág. 436) apresentou uma classificação em oito "tipos de tempo" que seriam "fundamentais" e que ocorreriam com frequências mais ou menos definidas, no Brasil Meridional. Porém, o que êsse autor chama de tipo "francamente distinto" (tr. cit., pág. 433) nada mais é do que uma condição média, de predomínio temporário e sucessivo, das massas de ar. Sampaio Ferraz admite que há "múltiplas nuanças" (obra cit.) das condições que ele chama tipo de tempo. Julgamos, porém, preferível considerar essas "múltiplas nuanças" como sendo os verdadeiros tipos de tempo - ao envez de o fazer para as condições gerais de que resultam.

Reconheço que a partir da contribuição de Ary França (1946) os estudos do clima no Brasil, no âmbito da Geografia, começaram a adquirir seu caráter mais apropriado e, paulatinamente, a abandonar o viés meramente meteorológico. Reconheço, também, que dessa fase de intensos debates sobre a dinâmica atmosférica, e de importantes contribuições geográficas à sua compreensão - os primórdios da análise geográfica do clima no país - Carlos Augusto de Figueiredo Monteiro participou intensamente, desde o início de sua vida universitária ${ }^{8}$.

Sua produção consistente é extremamente relevante para a Climatologia Geográfica Brasileira (MONTEIRO, 1962; 1963; 1964; 1968; 1969; 1971; 1973; 1976, 1980, 1991, 1999, 2000). Afinal, foi Monteiro quem buscou no conceito sorreano de clima o apoio necessário à proposição de um novo paradigma, a "análise rítmica" em climatologia, sem falar na sua inestimável contribuição aos estudos de climatologia urbana9. Reconheço, por fim, que o contato entre a Meteorologia e a Geografia é necessário - ousaria dizer fundamental - o que me leva a resgatar algo que já foi dito pelo iminente geógrafo:

[...] Tenho consciência de chocar alguns colegas quando estabeleço relações disciplinares deste tipo: o conceito de ano-seco e ano-chuvoso implica em sérias diferenças do ponto de vista meteorológico e geográfico. Para o primeiro, é bem explicitamente, um ano em que a pluviosidade total

8 "Minha análise geográfica do clima aplicada ao Brasil, iniciada nos anos quarenta assentou numa iniciação meteorológica fruída da obra de Adalberto SERRA. Naqueles tempos heróicos, onde a formação específica inexistia entre nós, SERRA, um engenheiro politécnico, adquirira uma admirável visão da meteorologia do continente sulamericano advinda de uma intensa experiência vivida, debruçada sobre o quotidiano das cartas sinóticas e análise de dados que, embora precários - sobretudo se comparados ao fastígio de hoje, com satélites meteorológicos e computadores - lhe conferiram um conhecimento da circulação atmosférica da América do Sul, sobretudo intuída graças a uma especial sensibilidade à geografia continental e do nosso País. Daí, ter a obra daquele meteorologista pioneiro sido da maior utilidade aos meus propósitos geográficos". (MONTEIRO, 1991, p.3)

9 A obra "Estudos do Clima no Brasil" (ZAVATTINI, 2004) traz um inventário da produção científica em Climatologia Geográfica (período 1971-2000), e revela o tempo e o espaço do ritmo do clima no país. 
se afastou dos parâmetros médios. Para a Geografia, além de ser importante sobrepor o modo de distribuição no decorrer do ano, em virtude do impacto desses desvios nas atividades humanas, os próprios parâmetros de referência não devem ser balizados pela estatística meteorológica, mas, sim, em função dos limites das necessidades humanas na organização e exploração do espaço geográfico. Aos que me dizem que isso é absurdo, pois que, uma vez clima, prevalece o meteorológico, eu pergunto se valeria a pena praticar uma disciplina que tendo um campo de investigação que se confunde com a própria Terra, não contasse com a possibilidade de ter um centro de interesse próprio e seus próprios parâmetros de referência. (MONTEIRO, 1976, p. 30-31)

Para além do que já foi dito e escrito, creio ser conveniente relembrar - ainda uma vez - os motivos que impulsionaram esse importantíssimo geógrafo a procurar e a encontrar um novo paradigma para os estudos do clima no Brasil, conforme a explicação que segue:

[...] Eu posso honestamente depor para vocês que na minha formação acadêmica as disciplinas de Climatologia estiveram sempre entre as mais aborrecidas do espectro curricular. E, a meu ver, a explicação deste fato tinha a ver: a) com a vinculação físico-matemático - melhor dizendo 'estatístico'; b) com a 'overdose' de meteorologia a ponto de criar uma situação de desconfortável ambigüidade entre os objetivos superpostos nos dois campos; c) o destaque que se dava às tipologias climáticas oriundas de sistemas de classificação de bases conceituais e metodológicas muito inconsistentes aos verdadeiros propósitos geográficos. E isto tanto foi válido para minha formação brasileira (194750) quanto pela complementação realizada na França (1951-53). Tanto no Curso de Geografia e História da antiga Faculdade Nacional de Filosofia da Universidade do Brasil no Rio de Janeiro, quanto na Faculté des Sciences da Universidade de Paris (Sorbone). Na primeira, o Professor Leuzinger, um engenheiro, enfatizava os aspectos 'físicos' da Atmosfera, e sua aparelhagem de mensuração. Na segunda, o Professor Tellier, um politécnico diretor do Parque Meteorológico de St. Maur, nos arredores de Paris, reforçava a perspectiva meteorológica em detrimento do caráter geográfico. Quando as circunstâncias colocaram-me à frente da cadeira de Geografia Física, nos idos de 1955 aqui nesta Florianópolis, na então Faculdade Catarinense de Filosofia - o germe da UFSC - eu tratei de esforçar-me para dar um tratamento menos aborrecido ao ensino da climatologia (MONTEIRO, 1999, p. 8).

Foi também a partir de 1955 que Mario Pinna, na Itália, tentaria dar um caráter mais geográfico e menos meteorológico-estatístico à Climatologia daquele país. Mais adiante serão mostrados alguns dos principais documentos que consegui levantar a respeito dessa discussão, que ainda hoje é crucial para o avanço dos estudos do clima em qualquer parte do mundo.
Mas, a seguir, tento resgatar os princípios que norteiam a Climatologia Geográfica Brasileira, graças aos esforços do Professor Monteiro. São os mesmos princípios que ao longo dos anos cinquenta e sessenta do século XX foram muito bem acolhidos por Mario Pinna na Itália, mas que, ao final dos anos setenta daquele século, surpreendentemente, ele iria rechaçar.

\section{O debate sobre o clima}

\subsection{Estado médio da atmosfera, totalidade dos tipos de tempo ou sucessão habitual dos esta- dos atmosféricos?}

No âmbito da Geografia Francesa, a definição de clima de Maximilen Sorre (1943, p. 13-14) "[...] On appelle climat la série des états de l'atmosphère au-dessus d'un lie dans leur succession habituelle.[...]", foi amplamente divulgada por Pierre Pédelaborde (1954; 1959; 1970; 1991), propositor do "método sintético das massas de ar e dos tipos de tempo", que precedentemente utilizara na tese de doutoramento sobre o clima da Bacia Parisiense (PÉDELABORDE, 1957).

Ao detalhar o seu método Pédelaborde (1991, p.22) explica que ao invés

[...] de séparer les éléments du temps dès le point de départ, la méthode synthétique a pour source essentielle les types de temps. Certes, chaque type sera analysé en ses éléments constitutifs (température, nébulosité, etc...). Mais on n'extraira pas ces éléments pour les faires entrer dans des calculs où ils seraient isolés des autres composants. Ce qui importe, c'est la façon dont le complexe se manifeste, le tableau qu'il réalise et l'action physiologique qu'il exerce. Ce qui importe aussi, ce sont les conditions qui déterminent ce complexe: d'où provient la masse d'air, combien de temps a-t-elle séjourné sur le Bassin arctique, sur le $\mathrm{N}$ de l'Atlantique, dans les parages des Açores ou sur les steppes russes, quelle trajectoire suit-elle, de quels mécanismes physiques est-elle le siège, quelles dénaturations a-t-elle subies avant d'atteindre le point d'observation. Enfin la durée sera envisagée, ainsi que les phénomenes qui déterminent cette durée et qui mettent fin au type.

Pédelaborde (1991, p. 23), enfatizando o dinamismo atmosférico, conclui que somente um estudo pautado por esse método

[...] à condition qu'elle embrasse la totalité des types, qu'elle calcule leur fréquence et la façon dont ils se succèdent au cours d'une longue période, restituera l'ambiance vraie dont parle Sorre. Elle aura saisi la réalité des temps et la complexité vivante du climat. Elle seule fournira une conception génétique qui s'ajoutera aux données précieuses mais incomplètes de l'étude séparative. Elle possèdera donc déjà une valeur indiscutable au point de vue de la 
géographie physique pure. D'autre part, elle seule pourra nous mettre sur la voie de la synthèse totale qui est le rêve de tout géographe, parce que les réactions du milieu vivant n'ont pas grand'chose à voir avec les moyennes, mais dépendent des conditions vraies du temps, de leur durée et de leur succession.

Contudo, sabe-se que não é a totalidade dos tipos de tempo que conduz à verdadeira compreensão dos climas - seja o de um pequeno local da superfície terrestre ou o de uma grande região do nosso planeta - pois o ritmo climático é conseqüência da ação variada que os sistemas atmosféricos exercem sobre os continentes e oceanos, não bastassem suas interações com os diversos fatores geográficos que, por fim, produzirão inúmeras e distintas características climáticas que, em última instância, constituem o verdadeiro mosaico climático do planeta Terra.

No Brasil, Carlos Augusto de Figueiredo Monteiro - de modo diverso dos procedimentos adotados por Pédelaborde (1957), que procurou abarcar a totalidade dos tipos de tempo atuantes sobre a Bacia Parisiense propôs e conduziu seus estudos pela análise rítmica, paradigma que até hoje sustenta a Escola Brasileira de Climatologia Geográfica (ZAVATTINI, 2004).

É importante lembrar que esse paradigma não requer o emprego de longas séries temporais - já a totalidade dos tipos de tempo sim - ou de séries "normais" (recomendação da Organização Meteorológica Mundial OMM) como os lapsos 1931/1960 e/ou 1961/1990. Dados "normais" são médias estatísticas de diversos elementos do clima (temperatura, precipitação, pressão atmosférica, insolação, nebulosidade, etc.) incapazes de retratar a dinâmica do tempo (climatológico) - sucessão horária e diária dos estados da atmosfera - e do clima - sucessão habitual dos estados atmosféricos.

O uso da análise rítmica requer apenas a escolha de "anos-padrão" - representativos dos diferentes ritmos climáticos (habitual e excepcionais) - ou de "períodos -padrão", inferiores a um ano, como por exemplo, uma dada estação do ano, ou alguns meses de um determinado ano, ou uma seqüência ininterrupta de determinado número de dias (análise episódica).

Na Itália o engajamento de Pinna nos estudos sobre a dinâmica das massas de ar e dos tipos de tempo antecede àquele pioneiramente manifestado, no Brasil, por Monteiro $(1962 ; 1963 ; 1964 ; 1968 ; 1969)$. Provam-no, a seguir, três importantes artigos escritos pelo geógrafo italiano.

\section{A pesquisa propriamente dita}

\subsection{A climatologia dinâmica é geográfica?}

No primeiro artigo, chamado "Climatologia Dinamica e Geografia" e publicado no "Bollettino della Società Geografica Italiana", ao fazer referência à primeira edição do livro "Introduction à l'étude scientifique du climat", de Pierre Pédelaborde (1954), Pinna (1955, p.143) sustenta que a climatologia dinâmica "[...] è la nuova disciplina sorta e sviluppatasi in questi ultimi decenni per lo studio sintetico dei fenomeni dell'atmosfera [...]", e que um de seus aspectos mais interessantes "[...] è lo studio delle masse d'aria nelle loro caratteristiche fisiche, nella loro evoluzione, nella loro influenza sul tempo e sul clima [...]". Pinna (1955, p.144) também mostra que há:

[...] un chiaro rapporto di interdipendenza tra massa d'aria e ambiente geografico, ed è questo l'aspetto della nuova disciplina che maggiormente interessa il geografo. Lo prova il fatto che per comprendere questi rapporti nella loro pienezza, per fissare i limiti medi di influenza delle singole masse d'aria, lo stesso studioso di climatologia dinamica ha bisogno di conoscere la superficie terrestre nei tratti generali del suo aspetto fisico (distribuzione delle terre e delle acque, barriere orografiche, ampie superfici libere o passaggi obbligati per le masse d'aria), nelle sue differenziazioni regionali e in diverse sue particolarità); deve pertanto acquistare uma certa familiarità con la scienza geografica, impiegando metodi di studio e concetti che le sono propri, infine deve servirsi come base principale di ricerca della carta fisica per interpretare opportunamente le situazioni del tempo.

Ainda nesse artigo é muito importante o trecho em que Pinna (1955, p.145) destaca:

[...] È importante sottolineare che la definizione del Sorre si fonda sulla considerazione degli stati o combinazioni più o meno duraturi che si realizzano nell'atmosfera, e questi null'altro sono se non i tipi di tempo della moderna climatologia; e che essa tiene conto della successione di questi tipi, ossia del ritmo di evoluzione dei fenomeni atmosferici, considerazione indispensabile per uma esatta conoscenza del clima e dell'azione che esso esercita sugli esseri viventi.

Não menos importante é o momento em que Pinna (1955, p.146) põe em relevo a contribuição de Pédelaborde e a adjetiva positivamente:

[...] Assai di recente il Pedelaborde [1954] in un lavoro di alto interesse ha sostenuto come indispensabile per la geografia la completa conoscenza dei risultati della nuova disciplina, come di tutte le altre che studiano i fenomeni fisici sulla superficie terrestre, al fine di poter operare una sintesi veramente efficace. L'A. tratta quindi nel suo volume i principali problemi della meteorologia dinamica, proponendosi di renderli accessibili ai geografi.

No segundo artigo, intitulado "Moderne vedute sulla circolazione generale dell'atmosfera" e publicado na revista "L'Universo", Pinna (1956) comenta os avanços da climatologia dinâmica e, ao longo do trabalho, cita várias obras que hoje são consideradas clássicas ${ }^{10}$ Ao discutir 
os processos físicos criadores da energia necessária à circulação atmosférica Pinna (1956) alude, novamente, à obra "Introduction à l'étude scientifique du climat" (Pédelaborde, 1954), que ajudou a disseminar, tanto na França e Itália como no Brasil, a definição de clima proposta por Sorre (1943). Os trechos selecionados desse artigo de Pinna (1956, p. 419) dão conta do quanto ele estava interessado pelos avanços alcançados pela climatologia dinâmica de então, e são transcritos a seguir:

[...] Riconosciuto dunque il carattere essenzialmente zonale della circolazione atmosferica e l'influenza che hanno i venti occidentali in quota [...] sull'evoluzione giornaliera del tempo [...] dato che il movimento dell'aria è prevalentemente zonale, occorre spiegare in qual modo si sposti verso i poli l'eccesso di calore e di umidità delle regioni equatoriali [...] Si ammette oggi che questi scambi avvengono, effettivamente, ma non in forma di correnti meridiane tra il polo e l'equatore, e viceversa, ma saltuariamente, con l'intermediario delle masse d'aria, e si attribuisce al fenomeno della turbolenza a grande scala il compito di realizzare questi scambi(19). Sono le grandi perturbazioni della zona temperata che creano la turbolenza a grande scala, in quanto determinano il trasporto orizzontale (per migliaia di $\mathrm{km}$ ) e verticale (fino ai limiti della troposfera) di masse d'aria e che realizzano appunto questi scambi saltuari: spostamenti d'aria fredda verso sud negli strati più bassi e di aria calda verso nord e verso l'alto, ciò che avviene appunto nell'evoluzione dei cicloni, secondo lo schema ormai classico della scuola norvegese $[\ldots]{ }^{11}$

No terceiro artigo, cujo título é "La climatologia come disciplina geografica" e está publicado na revista "Cultura e Scuola", Pinna (1964, p.136) retoma a contribuição pioneira de Pédelaborde e declara que ele foi:

[...] il primo (1954) a darci un trattato di climatologia nel quale vengono esposte con grande rilievo le recenti acquisizioni e le relative teorie sulla circolazione atmosferica, delle quali sono messi in evidenza gli aspetti più importanti dal punto di vista climatologico. Nello stesso anno il Pédelaborde, in una introduzione allo studio scientifico del clima, aveva esposto con chiarezza le basi dell'indagine sulla circolazione atmosferica ai fini dello studio del clima. Al Pédelaborde, che è certamente il maggiore esponente di questa nuova tendenza della climatologia, spetta pure

10 On the general circulation of the atmosphere in middle latitudes (ROSSBY, 1947); On the nature of the general circulation of the lower atmosphere (ROSSBY, 1949); Les grands mouvements de l'atmosphère (QUENEY, 1954); Wind and weather in equatorial zone (CROWE, 1951); The general circulation of the tropical and equatorial atmosphere (FLETCHER, 1945)", são algumas das que, dentre outras, foram citadas por Pinna (1956; p.403-420)

11 O teor da nota de rodapé (19) é o seguinte: "[...] Una simile ipotesi era stata formulata fin dal 1921 dal DEFANT A., Die Zirkulation der Atmosphäre in der gemassigten Breiten, Geogr. Annaler, III, 1921, p.209. (Riportato da PEDELABORDE P., Introduction à l'étude scientifique du climat, Centre de Docum. Univ., Parigi, 1954) [...]". (PINNA, 1956, p. 419) il merito di aver pubblicato la prima monografia regionale, riguardante il bacino parigino, redatta secondo i principi e coi metodi della climatologia dinamica. Tale studio è particolarmente importante, da un lato in quanto rappresenta un modello da seguire in ricerche del genere e dall'altro perché contiene una introduzione di carattere metodico nella quale viene difesa la tendenza a estendere $l^{\prime}$ indagine climatica al campo dinamico. I punti principali delle vedute del Pédelaborde possiamo qui riportare, in quanto esse esprimono non solo il pensiero di questo geografo francese, ma anche quello di tutti coloro (e sono ormai la maggior parte dei cultori di geografia fisica) che sostengono la necessità del rinnovamento della climatologia. Il Pédelaborde afferma dunque che il geografo deve considerare i fatti dinamici poiché questi gli consentono di spiegare le cause formatrici del clima, ma aggiunge pure che il geografo non può e non deve sostituirsi al meteorologo negli studi sulla dinamica atmosferica. Infatti più che la circolazione generale in sé e per sé, che è un fenomeno planetario e in parte anche cosmico, al geografo interessano (a parte una buona visione sintetica d'insieme) le circolazioni regionali, le quali mostrano meglio l'influenza dei fattori geografici; e se è vero che molti aspetti della circolazione atmosferica devono ancora essere spiegati, è pur vero che ai fini della climatologia dinamica interessa conoscere $\mathrm{i}$ meccanismi della circolazione e non i determinanti di tali meccanismi. Ciò che noi ignoriamo sono le cause profonde di questi meccanismi e in particolare l'origine dell'energia che assicura la circolazione atmosferica; ma quest'ultima e in particolare le circolazioni regionali appaiono nettamente nella carta meteorologica e a queste occorre che il geografo rivolga la sua attenzione.

Foi desse modo que a colaboração entre a climatologia dinâmica e a geografia (PINNA, 1955), apropriando-se dos aportes da moderna visão sobre a circulação geral da atmosfera (PINNA, 1956), passou a oferecer à comunidade científica daqueles anos a possibilidade de encarar a climatologia como uma disciplina geográfica (PINNA, 1955; 1964), graças às novas interpretações sobre o tempo e o clima. Na França elas norteariam a tese de doutorado intitulada "Le Climat du Bassin Parisien" (PÉDELABORDE, 1957), ao passo que na Itália iriam sustentar, ao longo das décadas de cinquenta e sessenta do século XX, não apenas os trabalhos de Mario Pinna como, também, os de outros geógrafos que se engajariam no debate em curso, conforme se depreende de alguns exemplos que foram selecionados e que são apresentados a seguir.

\section{O engajamento de outros geógrafos ita- lianos no debate do clima.}

No capítulo intitulado"Il Clima" que integra o livro "L'Italia Fisica", publicado pelo Touring Club Italiano, Alberto Mori (1957, p.21) narrava e explicava que a 
[...] varietà delle condizioni geografiche e il fatto che l'Italia si trova in una zona sottoposta a influenze atmosferiche e quindi a condizioni meteorologiche assai mutevoli, imprime altresì al clima italiano una considerevole incostanza, cioè um comportamento alquanto diverso da un anno all'altro, che è forse tra le sue principali caratteristiche [...] [ concluindo que] [...] La determinazione e l'esplicazione dei caratteri del clima non possono perciò essere condotte solo in base all'analisi dei dati sulla temperatura, sulla pressione atmosferica e sull'umidità secondo il sistema tradizionale dei valori e delle frequenze medie, bensì prendendo in considerazione anche i tipi di tempo, che più di frequente interessano il nostro Paese (p.21).

Osvaldo Baldacci (1961, p.182) no artigo "Nuove Interpretazioni Climatologiche", publicado na revista "Cultura e Scuola", afirmava que no âmbito "[...] della scienza geografica, la climatologia ha cominciato ad assumere una propria fisionomia soltanto nella seconda metà del secolo scorso, con lo sviluppo raggiunto dalla meteorologia [...]" e prosseguia mostrando que do final do século XIX ao início do século XX “[...] compaiono i trattati di meteorologia, di climatologia e alcuni atlanti climatici [...]", além de destacar que "[...] La prima trattazione esclusivamente climatica dell'Italia è comparsa nel 1909 ed è stata opera di G. Roster. Tra i contributi sucessivi, uno dei più completi è quello di Alberto Mori, pubblicato nel volume L'Italia fisica edito dal Touring Club Italiano [...]", obra supramencionada. Baldacci (1961, p.183) não deixava dúvida sobre quão importante era a Climatologia Dinâmica, sustentando que

[...] una climatologia senza attributi o è atipicamente generale o è un concetto astratto, tanto cammino ha fatto in questi ultimi anni la specializzazione meteorologica. Su questa strada avanzano meteorologi e geofisici, scrutando nuovi orizzonti e formulando nuove teorie, e arrichendo con nuove concluzioni quelle premesse dalle quali s'inizia l'elaborazione geografica. La ciclogenesi e la frontogenesi, l'identificazione di determinati percorsi di masse d'aria e la conoscenza delle leggi delle loro oscillazioni orizzontali e verticali, sono tutti argomenti d'impostazione causale, che la climatologia non può ignorare e che costituiscono un'introduzione istituzionale al vasto, complesso e ancora da sfoltire campo della ricerca climatologica. In tal modo i tipi di tempo in cui si concretano in definitiva i fatti dinamici dell'atmosfera, conferiscono alla climatologia tradizionale un'apertura a pieno giro, facendola respirare con la puntualizzazione di fenomeni caratteristici, nei qualli si esprimono e si estrinsecano in concomitanza elementi meteorologici e fattori geografici.

Em 1967, decorridos dez anos daquela contribuição de Mori (1957), veio a público um livro portentoso, de Cristofaro Mennella, intitulado "Il Clima d'Italia: nelle sue caratteristiche e varietà e quale fattore dinamico del paesaggio", com mais de 700 páginas distribuídas por 22 capítulos, sendo que dois deles inteiramente dedicados à Climatologia Dinâmica. O mais abrangente, trata da circulação atmosférica vigente em toda a Europa Ocidental (Parte I, capítulo 2, p. 102-141); já o mais específico, detalha as massas de ar e as frentes que agem sobre a Itália (Parte II, capítulo 20, p. 692-717). No prefácio da obra Mennella (1967, p.5-7) define o clima como sendo:

[...] quell'insieme di fenomeni atmosferici periodici od occasionale che con la loro specifica frequenza, la diversa entità, il modo particolare di manifestarsi e di susseguirsi, influendo costantemente sul suolo e ancor più spiccatamente sui vegetali e sugli animali ed in specie sull'uomo conferiscono alla sua vita un tono, un ritmo, un particolare comportamento espressivo ed emotivo - che poi ne rappresenta una delle maggiori attrattive, è noto nei tratti essenziali e in alcune delle sue varietà benchè le conoscenze ad esso relative non siano così profonde, estese e divulgate come per gli altri fattori concorrenti [...] [e revela que nessa obra] L'indirizzo seguito è dunque quello classico, ossia della Climatologia che potremmo dire statica, ma opportunamente integrato con quello dinamico oggi di attualità [...] [Mennella também destaca o seguinte:] [...] Infatti vengono convenientemente considerati anche gli "individui" e le formazioni bariche primarie e secondarie come le "masse d'aria", i "fronti", le ciclogenesi, le aree di alta pressione (o anticicloni), le traiettorie delle depressioni. Come è noto, talune di dette formazioni risultano pressochè stazionarie su determinate zone della superficie terrestre e condizionano o caratterizzano il loro clima almeno nelle linee generali; altre trasmigrano da una zona all'altra seguendo dei percorsi ormai ben conosciuti, provocando mutamenti occasionali, più o meno rilevanti, dello stato del tempo meteorologico contingente nell'ambito della propria sfera d'azione.

É praticamente impossível descrever toda a riqueza de informações contida nesses dois capítulos voltados à climatologia dinâmica, embora seja possível afirmar que foram essenciais às análises rítmicas praticadas na Itália, junto com Simona Fratianni, correlacionando dados climáticos diários e dinâmica atmosférica aos esportes de inverno nos Alpes Piemonteses (FRATIANNI \& ZAVATTINI, 2007; 2009), bem como à produção vitivinícola no "terroir" do Barolo (FRATIANNI \& ZAVATTINI, 2006).

\section{De volta à contribuição de Mario Pinna.}

Prosseguindo na linha do tempo do desenvolvimento da Climatologia Geográfica na Itália, logo após a publicação do grande livro de Mennella (1967), mais precisamente no ano de 1969, surgiriam duas novas contribuições de Mario Pinna. Na primeira delas, intitulada "La Distribuzione Geografica della Temperatura dell'Aria in Italia" e publicada na revista "Cultura e Scuola", Pinna (1969, p.142) dedicaria apenas um pará- 


\section{grafo à Climatologia Dinâmica:}

[...] I fattori che possono spiegare queste sensibili variazioni del gradiente termico di altezza da una regione all'altra sono numerosi: la diversa esposizione dei rilievi nei riguardi della radiazione solare, la diversa intensità con cui essi sono interessati da masse d'aria fredda e calda che giungono sul territorio italiano, e infine le condizioni geografiche locali, che favoriscono o meno il verificarsi delle situazioni di inversioni termica.

Já a partir da segunda contribuição, chamada "Le Variazioni del Clima in Epoca Storica e i loro Effetti sulla Vita e le Attività Umane"e publicada no "Bollettino della Società Geografica Italiana" (1969, p.198-275), Pinna passaria a adotar uma perspectiva mais histórica e toda ela desvinculada dos aspectos geográficos da circulação atmosférica, até então, objeto de suas constantes considerações climatológicas (PINNA, 1955; 1956; 1964).

É surpreendente ver que no artigo intitulado "Contributo alla classificazione del clima d'Italia" e publicado na "Rivista Geografica Italiana", Mario Pinna (1970, p.130) ao invés de propor uma classificação climática de base genética para a Itália - já que cedo demonstrara grande interesse pela dinâmica das massas de ar e dos tipos de tempo - se retrai e aplica o sistema de Köppen, alegando a necessidade "[...] dei raffronti tra le condizioni che offre l'Italia e quelle di altri paesi della zona temperata i cui climi siano stati studiati e classificati sulla base del predetto sistema (vedi tavola a colori)". É também decepcionante vê-lo insatisfeito com a carta temática obtida a partir do uso daquele sistema, pois que Pinna (1970, p.130) o modifica com a seguinte justificativa:

[...] Dato però che questo non dà, a mio parere, risultati pienamente soddisfacenti per il territorio italiano (per le ragioni che esporrò più avanti), ho ritenuto opportuno introdurre nella classificazione del Köppen alcune modificazioni riguardanti i climi temperati, al fine di ottenere una suddivisione più rispondente alle particolari condizioni che offre il nostro paese. Le modificazioni apportate riguardano soltanto il regime della temperatura e non quello delle precipitazioni. Ho quindi costruito la carta dei tipi così individuati (tav. II) .[...] Mi auguro che il raffronto tra le due carte possa offrire ad altri studiosi l'occasione per un ulteriore approfondimento del problema e per un'indagine ancor più attenta, dalla quale possa scaturire una soluzione definitiva e veramente razionale.

Não obstante lamentar-se por não ter alcançado grandes resultados com a aplicação do sistema climático de Köppen e ansiar por estudos mais aprofundados do clima da Itália, Pinna (1970, p.131) demonstra estar conformado, pois assim discorre:

[...] D'altra parte riconosco che vi è del vero nell'opinione espressa da diversi autori, secondo cui non esiste una classificazione dei climi valida in senso universale, bensì tante classificazioni quante sono le esigenze dei vari studiosi (geografi, geologi, botanici, meteorologi, ecc.), poiché quella fra tutte che meglio risponde ai bisogni del geografo, il quale ha presente la distribuzione di particolari paesaggi e di particolari aspetti del modellamento del terreno, può non soddisfare il botanico, cui interessano le relazioni esistenti fra i caratteri del clima e la distribuzione delle principali formazioni vegetali o gli areali di certe specie tipiche, e può non soddisfare il meteorologo, che da parte sua tende a classificare i climi in funzione della distribuzione di certi fenomeni dinamici dell'atmosfera. Anche se ciò è vero, il problema di una razionale classificazione del clima rimane importante e merita di essere affrontato; le due carte che qui presento vogliono essere ad ogni modo soltanto un primo contributo alla migliore conoscenza dei climi italiani e della loro distribuzione geografica.

Mario Pinna, embora tenha tido a oportunidade de propor uma classificação climática de base genética para a Itália, em obras subsequentes de grande envergadura ("Climatologia", 1977; “L'Atmosfera e Il Clima", 1978), não o fez. Por que? Foi por conformismo ou porque teve dúvidas a respeito da definição de clima de Sorre e do método sintético das massas de ar e dos tipos de tempo de Pédelaborde? São perguntas sem respostas. O que se sabe é que no artigo intitulado "Precipitazioni Nevose e Durata del Manto Nevoso in Italia", publicado na revista "Cultura e Scuola", Pinna (1974, p.144-145) ele retomaria a temática dinâmica e explicaria que as situações sinóticas:

[...] favorevoli alle cadute di neve sono assai varie, ma possiamo dire, in linea del tutto generale, che mentre nelle nostre zone di pianura e nei litorali le nevicate sono legate a consistenti afflussi di masse d'aria fredda dai quadranti settentrionali, nell'arco alpino si verificano piuttosto con venti meridionali connessi con profonde depressioni atmosferiche e particolarmente coi fronti caldi di queste ultime: è il caso delle "neiges de redoux", di cui parla il Péguy (2). Apportatori di abbondante umidità, questi venti danno cospicui quantitativi di pioggia in pianura e neve in montagna, a partire dalla quota in cui il raffreddamento dell'atmosfera impone il formarsi di precipitazioni solide. Occorre tuttavia precisare che le nevicate concomitanti con le correnti aeree dei quadranti settentrionali, cui si deve l'apporto sulle nostre regioni di aria intermedia o addirittura di aria artica, si possono avere anche nell'arco alpino all'inizio della stagione fredda, quando l'ambiente atmosferico della grande catena montuosa è ancora in qualche misura influenzato dall'aria mediterranea, tiepida e umida; altrettanto si può dire per le aree più elevate dell' Appennino. Invece per le zone di pianura e per le basse montagne della parte peninsulare e insulare dell'Italia l'irruzione di masse d'aria fredda da nord e da nord-est rappresenta la sola situazione meteorologica capace di determinare cadute di neve(3) [...]. 
Entretanto, num de seus livros mais clássicos, simplesmente chamado "Climatologia" (1977), publicado em 11 capítulos e com 442 páginas, Pinna dá bons indícios da guinada que daria na sua produção científica. Tanto é assim que já na introdução da obra, subtítulo "La Moderna Scienza del Clima", Pinna (1977, p.1) se esquece dos "velhos" ensinamentos de Sorre e de Pédelaborde e dá preferência à definição de clima de Hann, pois afirma que:

[...] Oggi sappiamo che il clima differisce dal tempo in quanto, mentre quest'ultimo rappresenta una combinazione momentanea dei vari elementi meteorologici su un dato luogo, derivante dalla presenza d'una particolare massa d'aria o di diverse masse d'aria in contrasto fra loro, il clima invece è dato dall'insieme delle condizioni tipiche che si verificano nel corso dell'anno; esso è dunque la risultante di tutte queste situazioni del tempo e rappresenta lo "stato medio" dell'atmosfera su quel dato luogo.

E como se não bastasse tal afirmação, Pinna (1977, p.12) prossegue com sua linha de raciocínio explicando que:

[...] Il tempo è solo una situazione fugace, e ciascun individuo, in quanto vede e sente il tempo, avverte questo senso di rapida evoluzione che sembra non lasciare traccia alcuna. Eppure le tracce rimangono e continuano a esercitare più o meno a lungo i loro effetti e a influenzare altri fenomeni fisici. Queste conseguenze, questa somma di influenze esercitate dalle pur mutevoli condizioni del tempo creano il clima. Tuttavia ciò che noi dobbiamo intendere esattamente sotto questo concetto non è cosa ovvia e naturale, come molti pensano, ma lo fissiamo dopo una serie di astrazioni e dopo aver ricomposto in un quadro di sintesi tutte quelle conoscenze fondamentali sulla temperatura dell'aria, l'umidità, la pressione atmosferica, ecc., che sono state acquisite dai meteorologi con i loro studi analitici condotti su basi fisico-matematiche, da quando si è cominciato a disporre di misurazioni precise di questi elementi meteorologici ottenute con strumenti adeguati e per periodi di tempo sufficientemente lunghi.

Definitivamente, Sorre e Pédelaborde não mais exerciam influência sobre o grande geógrafo italiano Mario Pinna, pois ao tratar do papel exercido pelo geógrafo alemão A. Hettner ele destaca:

[...] che fu tra i primi (1930) a esprimere la sua insoddisfazione per il carattere eccessivamente descrittivo e statico della climatologia a lui contemporanea, aveva detto che questa scienza non deve accontentarsi della constatazione descrittiva dei datti di fatto, bensì deve tentare di spiegarli, fin dove è possibile, con lo studio dei fenomeni atmosferici [...] [E, categoricamente, afirma que] [...] Dopo Hettner molti si convinsero che sarebbe stato possibile pervenire a un'efficace descrizione del clima di una regione soltanto attraverso l'esame delle masse d'aria, dei cicloni e antici- cloni solitamente interessanti quella regione. Nacque così, poco prima della seconda guerra mondiale, la Climatologia dinamica, che trovò subito entusiastici sostenitori, i quali per altro si resero conto ben presto che per ricerche del genere rimaneva la difficoltà della grande scarsezza dei dati a disposizione. Infatti in ogni paese sono assai pochi gli osservatori che fanno rilevazioni in quota per precisare le caratteristiche delle masse d'aria e i rapporti tra la circolazione al suolo e quella della media e alta troposfera. Si calcola infatti che nei paesi evoluti mentre è possibile trovare una stazione termometrica o pluviometrica ogni 200-300 kmq, si ha invece un solo osservatorio meteorologico ogni 100-120 mila kmq (escluse le zone artiche). Date queste obiettive difficoltà, la climatologia dinamica non ha potuto trovare una larga diffusione. D'altra parte nel secondo dopoguerra la climatologia tradizionale ha ripreso nuovo vigore, specialmente dopo che alcuni studiosi, come H. E. Landsberg e C. W. Thornthwaite, hanno dimostrato che essa non solo era capace di percorrere vie nuove (Thornthwaite ha introdotto il concetto di "evapotraspirazione potenziale") ma che poteva essere di valido aiuto nello studio di certi problemi agrari (irrigazione, trasformazione agraria, ecc.) soprattutto nel vasto mondo dei paesi arretrati. Quanto ai paesi industrializzati, il recentissimo sviluppo degli studi sulla protezione dell'ambiente naturale e sulla lotta contro gli inquinamenti ha riportato decisamente in primo piano la climatologia classica per il prezioso ausilio che essa può dare nella soluzione di questi problemi e l'ha legata con vincoli ancora più stretti alle discipline biologiche e alla ecologia umana. (PINNA, 1977, p.3-4)

Para que não pairem dúvidas sobre os novos caminhos que iria trilhar Pinna (1977, p.4) explica:

[...] L'opinione oggi più diffusa è che il climatologo deve bensì considerare i fatti dinamici poiché questi gli consentono di spiegare le cause formatrici del clima, ma che egli non può e non deve sostituirsi al meteorologo negli studi sulla dinamica atmosferica. Infatti più che la circolazione generale in sé e per sé, che è un fenomeno planetario e in parte anche cosmico, al climatologo-geografo interessano (a parte una buona visione d'insieme) gli aspetti regionali della circolazione e l'evoluzione giornaliera del tempo, che appaiono nettamente dall'esame delle carte meteorologiche di un lungo periodo. Comunque, negli studi climatologici regionali, come nella climatologia generale (classificazione dei climi), l'impiego delle medie climatiche care alla vecchia climatologia rimane di fondamentale importanza. Infatti solo questi valori medi possono mettere in evidenza certe sfumature altrimenti non rilevabili, ossia certe "facies" di dettaglio che sfuggirebbero certamente alle maglie troppo larghe dello studio condotto solo su considerazioni di ordine dinamico. Possiamo concludere dicendo che le due parti dello studio climatico sono egualmente importanti e che non è lecito contrapporre una "climatologia classica" (sintetico-statistica), basata solo sull'esame dei valori medi, a una "climatologia moderna", fondata soltanto 
sulla considerazione delle vicende meteorologiche e della dinamica dell'atmosfera, poiché la "moderna climatologia" deve essere dinamica e statistica insieme.

São essas as pistas que ajudam a compreender porque Pinna (1977), ao realizar uma obra tão importante para a Climatologia Italiana, mesmo tendo dedicado dois capítulos à dinâmica atmosférica (Capítulo VII - "Masse d'aria - Fronti - Perturbazioni", p.227-264, e Capítulo VIII - "La circolazione generale dell'atmosfera", p.265-301), não abordou o clima da Itália sob a ótica dinâmica (genética) e preferiu tratá-lo de modo estático (separativo).

Mas a chave para a compreensão definitiva da guinada na produção climatológica de Mario Pinna encontrase num longo trecho do capítulo IX ("I climi e la loro classificazione", p. 302-347), em que Pinna (1977, p.320) questiona a validade do "método sintético das massas de ar e dos tipos de tempo" (PÉDELABORDE, 1954; 1970; 1991), conforme se depreende da transcrição a seguir:

[...] L'idea di considerare i grandi tratti della circolazione atmosferica per delineare una classificazione dei climi è senz'altro originale ed interessante e può certamente essere proficua di risultati, almeno se con questo metodo si vuole pervenire a una classificazione di base, cioè a una prima intelaiatura entro la quale ricercare un'ulteriore suddivisione con altri metodi che consentano un esame più particolareggiato della realtà climatica. A questo punto però ci poniamo un quesito: le classificazioni di questo tipo sono veramente impostate su basi "genetiche"? Cioè, esse si richiamano veramente alle cause formatrici del clima? Qualche dubbio in proposito ci sembra giustificato. Infatti si può obiettare che la stessa circolazione generale posta alla base di tali suddivisoni non è un fatto primario (e quindi non trova proprio all'origine dei climi) ma è anch'essa un effetto dell'economia della radiazione unita all'effetto di Coriolis. Da ciò deriva che anche le classificazioni basate sulla frequenza delle masse d'aria, che da alcuni autori vengono pure chiamate genetiche, in verità non sono affatto tali, perché la distribuzione delle masse d'aria e le modificazioni che queste ultime subiscono sono a loro volta una conseguenza della circolazione. A parte queste considerazioni di carattere teorico, nelle classificazioni che si basano sui sistemi di circolazione e in quelle che prendono per base le masse d'aria vi è l'inconveniente non trascurabile (e finora non superato) che i singoli tipi climatici non vengono delimitati da valori numerici (valori di soglia o di durata) e neppure da formule, onde è possibile stabilire solo approssimativamente l'appartenenza di una stazione meteorologica, e quindi dell'area che la circonda, ad un tipo di clima o ad un altro simile; senza contare il fatto, cui già si accennava in precedenza, che la rete delle osservazioni sinottiche ha maglie troppo larghe per le esigenze del climatologo. È dunque evidente che molti progressi dovranno ancora essere compiuti in questo campo di ricerca prima che si possa giungere a classificazioni climatiche che siano coerenti e ad un tempo sufficientemente flessibili così da consentire la delimitazione di tipi e sottotipi entro le grandi classi dei climi. Pur con queste riserve, esaminiamo i più significativi tentativi di classificazione dei climi che poggiano su concetti di climatologia dinamica e sinottica.

Esse mesmo gênero de argumentação iria comparecer na obra sucessiva de Pinna (1978), intitulada “L'Atmosfera e Il Clima" e composta de 12 capítulos, distribuídos em 478 páginas. Dois desses capítulos são inteiramente dedicados à climatologia dinâmica (Capítulo VI - "Le perturbazioni atmosferiche", p.173-202; e Capítulo VII - "La circolazione generale dell'atmosfera", p.203-229), um deles está voltado aos climas da Terra (Capítulo IX - "Le classificazioni climatiche e i vari tipi di clima", p.290-359), sendo que outro ocupa-se dos climas italianos (Capítulo XI - "Il clima dell'Italia", p.435-474). Mais uma vez, evitando aplicar uma classificação de base genética à Itália, Pinna (1978, p.290-291) explica que os elementos meteorológicos:

[...] si combinano fra loro per formare il clima; e se pure consideriamo soltanto i valori medi, soprattutto quelli mensili ed annui, le combinazioni possibili rimangono così numerose che è quase impossibile per due luoghi della terra avere un clima identico [...]

Entretanto, no último capítulo, Pinna (1978, p.439) acaba oferecendo uma explicação sintética da ação exercida pelas massas de ar em estações contrastantes, pois informa que:

[...] d'inverno l'afflusso di masse d'aria umida e fredda (o temperato-fredda) da ovest e da nord-ovest porta sull'Italia tempo moderatamente freddo e piogge (neve nelle zone montane), mentre l'aria fredda e asciutta che giunge da nord-est porta giornate serene e luminose, per altro accompagnate da un sensibile abbassamento della temperatura: al suo arrivo, prima di imporsi stabilmente sull'Italia, quest'aria continentale può determinare abbondanti nevicate. In estate invece l'aria tropicale che invade tutto il bacino mediterraneo porta tempo asciutto, stabile e caldo.

Nas suas derradeiras considerações Pinna (1978, p.465) usa a seguinte argumentação:

[...] Possiamo concludere questo breve profilo della climatologia dell'Italia proponendo una classificazione del clima italiano dal solo punto di vista termico. Questa sintesi, che è scaturita da un attento esame della temperatura media annua, di quella dei mesi estremi e dei valori dell'escursione, è stata fatta improntando lo schema generale alla classificazione del Köppen [...] [E de modo esperançoso Pinna (1978, p.474) conclui sua obra dizendo] [...] ci auguriamo che la carta qui presentata possa da un lato offrire lo spunto per ulteriori studi sul clima dell'Italia e dall'altro dare utili indicazioni a coloro che si propongono di studiare in un quadro di sintesi i rapporti esistenti fra il clima e gli altri 
elementi del paesaggio italiano.

Desde então, Mario Pinna enveredaria pelo novo caminho que inaugurara - o da perspectiva histórica dos climas - e publicaria muitas obras, todas de grande importância, tais como "La Storia del Clima: variazioni climatiche e raporto clima-uomo in età postglaciale" (Memorie della Società Geografica Italiana, 1984), "Ipocrate: fondatore della teoria dei climi" (Rivista Geografica Italiana, 1988), "La Teoria dei Climi: una falsa dottrina che non muta da Ippocrate a Hegel" (Memorie della Società Geografica Italiana, 1988; Cultura e Scuola, 1989), "Le Variazioni del Clima: dall'ultima grande glaciazione alle prospettive per il XXI secolo" (FrancoAngeli, 1996), "La climatologia nella seconda metà del secolo XX: alcuni elementi per un riesame" (Bollettino della Società Geografica Italiana, 1998).

Contribuiria com inúmeros artigos, dentre os quais se destacam "L'Inquinamento Atmosferico in Italia: note climatico-ecologiche" (Bollettino della Società Geografica Italiana, 1988), "L'aumento della temperatura nel XXI secolo e la sua influenza sul livello dei mari" (Cultura e Scuola, 1990) e "La Geografia tra Cultura Scientifica e Cultura Umanistica: brevi annotazioni suggerite da una recente opera sulle catastrofi naturali" (Bollettino della Società Geografica Italiana, 1992).

E continuaria produzindo em climatologia, como demonstram os artigos: "Contributo allo studio del potere refrigerante del vento nelle aree montane d'Italia" (Bollettino della Società Geografica Italiana, 1989), “La Bioclimatologia Umana: lo sviluppo recente di un'antica disciplina” (Rivista Geografica Italiana, 1993), “Confort e Disagio Climatico in Italia: contributo di bioclimatologia" (Rivista Geografica Italiana, 1996), dentre outros. Também continuaria, vez por outra, a utilizar alguns preceitos da climatologia dinâmica, como no caso dos artigos "Il Soleggiamento in Italia: brevi note climatologiche" (Cultura e Scuola, 1986) e "Sui caratteri climatici dell' Arcipelago Toscano" (Rivista Geografica Italiana, 1991).

Organizaria, ainda, volumes especiais editados pela "Società Geografica Italiana", dos quais também participaria na qualidade de autor, como por exemplo "Contributi di Climatologia" (Memorie della Società Geografica Italiana, 1985) e "Le Variazioni Recenti del Clima (1800-1990) e le Prospettive per il XXI Secolo" (Memorie della Società Geografica Italiana, 1991).

\section{Homenagear os grandes, eternizar o de- bate ou superá-lo?}

Na Itália, diferente do que acontece no Brasil, os grandes mestres são homenageados com obras exclusivas, cujos conteúdos e colaboradores são reunidos por afinidade temática, comum a todos, inclusive ao homenageado. Foi assim que vieram a público dois volumes dos "Studi in Onore di Mario Pinna". O volume
I intitulado "Il clima e la storia del clima"; o volume II, "L'ambiente e le attività dell'uomo", ambos publicados nas “Memorie della Società Geografica Italiana" (1998), aos quais Pinna pode apreciar em vida. Mais tarde, "post-mortem", seria publicado o volume "Per Ricordare Mario Pinna" (Memorie della Società Geografica Italiana, 2003), sendo que todos os três volumes - tanto os de 1998 quanto o de 2003 - foram organizados por Paolo Ghelardoni.

Mario Pinna, um grande da Geografia Italiana, preferiu abandonar os ensinamentos de Sorre e as argumentações de Pédelaborde. Já Carlos Augusto de Figueiredo Monteiro, importantíssimo geógrafo brasileiro, adotou a definição de clima de Sorre, ponderou as deficiências do método separativo e as qualidades do método sintético de Pédelaborde, e propôs a "análise rítmica em climatologia", paradigma que sustenta - até os dias de hoje - a Escola Brasileira de Climatologia Geográfica (ZAVATTINI, 2004).

Encerrando a narrativa sobre o papel exercido por Mario Pinna na Climatologia Italiana, gostaria de mostrar que, enquanto no Brasil a Climatologia andava a passos largos, na Itália prosseguia a "eterna" discussão sobre o papel do geógrafo nos estudos do clima, como demonstram, a seguir, duas contribuições selecionadas com esse propósito.

No primeiro artigo, intitulado "I Lineamenti Essenziali della Meteorologia Geografica"e publicado na "Rivista Cultura e Scuola", Vittorio Cantù (1981, p.168-172), após um longo discurso introdutório, retrata-se ao afirmar que:

[...] Abbiamo introdotto una così sproporzionata divagazione nella speranza di evitare malintesi circa quella che vorremmo chiamare 'meteorologia geografica'. Essa può definirsi la meteorologia destinata a far sentire a proprio agio l'uomo generico dovunque egli vada, o più concretamente a fornire in forma esplicita e sistematica una conoscenza delle caratteristiche dei singoli comprensori, simile a quella posseduta in maniera più o meno conscia dagli individui e dalle comunità che vi siano insediati da gran tempo [...] [E prossegue mostrando que desde quando] [...] Aristotele stabili il nome 'meteorologia', questa s'è sempre interessata più ai fenomeni in sé che alla loro distribuzione geografica. Psicologicamente, il punto di vista dell'uomo comune è il luogo dove egli sta, e dal quale vede transitare i fenomeni meteorologici; invece il punto di vista del meteorologo è il cuore del fenomeno stesso, che egli vede dall'interno. Tale atteggiamento è accentuato dalla circostanza che i principali fenomeni meteorologici (dalle correnti a getto e dalle grandi saccature in quota, ai cicloni e anticicloni, alle masse d'aria e ai fronti fino ai temporali e alle trombe d'aria) hanno un'individualità e una vita. Riesce quindi comprensibile che finora sia stata ignorata sistematicamente una meteorologia geografica [...] [Cantù, decepcionado com o estágio de desenvolvimento das pesquisas aplicadas, declara] [...] L'agio o disagio che le condizioni meteorologiche di determinate località e regioni generano negli 
esseri umani non sembra invece avere studiosi specifici. Per esso hanno manifestato interesse - spesso vivo, però non molto costante - più che altri i meteorologi generici [...] [e conclui] [...] C'è ancora molto da fare per proporre indici appropriati alle diverse condizioni di vita. Ad esempio sembra che i passagi frontali e le precipitazioni si verifichino di preferenza in certi momenti della giornata. Se questi coincidono con l'andata al lavoro o peggio col ritorno (visto che a pochi si applica la definizione svizzera del meteorologo: 'Chi tiene un impermeabile a casa ed uno in ufficio') generano un disagio accentuato.

No segundo artigo, chamado "La Climatologia Geografica" e também publicado na "Rivista Cultura e Scuola", Osvaldo Baldacci (1986) resgata um artigo de sua autoria, publicado há 25 anos na mesma revista ("Nuove Interpretazioni Climatologiche", 1961), e como se não bastasse retoma o "velho" debate sobre o tempo e o clima, a climatologia dinâmica, as classificações climáticas, etc. Na conclusão de seu artigo Baldacci (1986, p.199) aproveita para (re)lembrar que a climatologia geográfica

[...] studia il fatto antropofisico negli aspetti maggiormente caratterizanti che discendono da elementi meteorologici locali, da fattori geografici più spiccati, e da comportamenti causali normali e anomali; ha come metodo di lavoro la valutazione sinottica della presenza partecipante dei singoli elementi ambientali (naturali e antropici) in azione e in reazione, in offesa e in difesa, considerati nella loro globalità; ha come fine la riduzione dei danni che possono derivare da eccessivi scostamenti dalla norma, e la amplificazione dei vantaggi che si possono ricavare dal clima per una migliore qualità della vita. Una volta recepita e considerata questa pluralità di adempimenti e di funzioni, ritengo di poter formulare una definizione di 'clima geografico', che capovolge tutte le nostre acquisizioni tradizionali, ma che riconduce il clima simultaneamente con i piedi sulla terra e sulla Terra: il clima geografico è una risposta attiva che si evidenzia nel paesaggio antropico, biologico e fisico; risposta che si adegua o reagisce alle causale vicenda meteorologica troposferica, considerata anche nei suoi avvenimenti eccezionali.

Mas houve - e há - pesquisadores na Itália que, ao invés de persistirem nas infindáveis discussões do papel da climatologia dinâmica (ou da geografia das massas de ar e dos tipos de tempo), preferiram - e preferem aprofundar o conhecimento da dinâmica atmosférica e de suas relações com as chuvas, a neve e o turismo. É o caso dos trabalhos de Marcelo Urbani ("Su una classificazione di tipi di tempo in Europa", 1955; "Sulla ciclogenesi nel Mediterraneo durante l'inverno", 1956), Alberto Latini ("Analisi della distribuizione delle precipitazioni nevose sulle Alpi italiane in relazione ai tipi di tempo e alle correnti in quota", 1987), Sergio Borghi ("Climatologia Dinamica dei Tipi di Tempo sul Veneto", 1983; "Tipi di Tempo e Distribuzione delle Precipitazioni sulla Montagna Veneta", 1987), e de Simona Fratianni, Augusto Biancotti e Alfio Giuffrida ("Clima e turismo marino: i tipi di tempo estive delle stazioni meteorologiche tirreniche", 2006), dentre outros.

Como a Climatologia Geográfica Brasileira não se perdeu em discussões estéreis sobre a climatologia dinâmica (ou sobre a geografia das massas de ar e dos tipos de tempo), e cedo se firmou nas bases lançadas por Monteiro (1962; 1963; 1964; 1968; 1969), cedo também viu a sua qualidade atingir patamares elevados, a tal ponto que já foram realizados dez Simpósios de Climatologia Geográfica no país, com a presença maciça de geógrafos e de outros pesquisadores dessa área do saber e uma produção consistente distribuída por diversas sessões de comunicação, mesas-redondas e conferências.

\section{Considerações finais}

De um lado, o extenso levantamento efetuado, cobrindo os estudos geográficos do clima produzidos entre os anos de 1950 e 2010 na Itália, foi capaz de reunir uma infinidade de obras e artigos voltados à climatologia. A soma das informações, neles contidas, traçou um amplo e variado painel das contribuições oferecidas por geógrafos italianos à Climatologia daquele país, dentre as quais se destacou, de modo indiscutível, a do geógrafo Mario Pinna. Do outro lado, um levantamento anterior e menos abrangente (1971-2000), já havia comprovado a forte influência de Carlos Augusto de Figueiredo Monteiro nos estudos do clima no Brasil (ZAVATTINI, 2004).

O levantamento bibliográfico executado em terras italianas mostrou, também, que o "despertar" de Pinna para a "noção de ritmo" de Sorre (1955) e o "método sintético" de Pédelaborde (1954; 1957) é praticamente concomitante ao de Monteiro. Entretanto, quando se considera o que cada um deles foi capaz de produzir, sob o impacto dessa fundamentação teórica, definitivamente, a balança se desequilibra a favor do geógrafo brasileiro.

É que ao passo que um recua, se abriga nos dados "normais" de trinta anos - recomendação da OMM - e usa a classificação climática de Köppen (PINNA, 1970; 1977; 1978), o outro avança, rompe com o desconforto das séries temporais mais curtas e propõe o uso de "anos-padrão" e da "análise rítmica" (MONTEIRO, [1964]1973; 1971) nos estudos de climatologia.

$O$ resultado de posturas tão diversas se reflete no que hoje, de palpável, a Itália oferece à compreensão de seus climas regionais, isto é, cartas climáticas baseadas em sistemas tradicionais, analítico-separativos (MENNELLA, 1967; MORI, 1957; PINNA, 1970; 1977; 1978; dentre outros). Entretanto, as cartas brasileiras, embora ainda muito presas aos sistemas tradicionais, já começam a traçar, pouco a pouco, o desenho do nosso verdadeiro "mosaico" climático regional (AOUAD, 1978; BOIN, 2000; FONZAR, 1990; MONTEIRO, [1964]1973; 2000; ROSSATO, 2011; SANT'ANNA NETO, 1990; SETTE, 
2000; ZAVATINI, 1990; ZAVATTINI, 2009).

Um "mosaico" que vem sendo delineado pelo emprego do sistema genético de classificação climática, e que está baseado nos princípios norteadores de Monteiro (1962; 1963; 1964). Um sistema sintético, capaz de integrar os índices de participação das massas de ar e dos mecanismos frontológicos aos volumes de chuva por eles engendrados, sem desconsiderar a distribuição geográfica desses índices (atmosféricos) e volumes (pluviais). $\mathrm{E}$, tudo isso, graças à "análise rítmica em climatologia" preconizada por Monteiro (1971), aplicada a diferentes "anos-padrão", representativos da sucessão habitual e/ou excepcional dos tipos de tempo que agem sobre uma dada região.

Todos esses fatos devem ser encarados como promissores, principalmente se consideradas a extensão territorial da Itália e a do Brasil, muito diferentes entre si, sem falar na configuração e morfologia de cada um desses países.

O que lá, em termos climatológicos e genéticos, a morfologia pode diversificar (Alpes, Apeninos, Vale do Pó, etc.), os mares que circundam a península itálica tratam de homogeneizar, principalmente no nível das planícies litorâneas do Mediterrâneo e do Adriático, enquanto nas ilhas (Sicília e Sardenha) há predomínio de climas heterogêneos.

Já por aqui, quando se pensa na gênese dos climas, é preciso dar particular atenção à distribuição (temporal e espacial) das chuvas. Nosso território, aparentemente mais monótono que o italiano e de dimensões continentais, apresenta uma diversidade pluvial bastante considerável, geneticamente ligada ao ritmo de sucessão dos tipos de tempo (habitual e excepcional), mas que também pode refletir - e reflete - traços específicos de nossa variada morfologia ("serras" litorâneas, chapadas interioranas, "cuestas" basálticas, etc.).

E não se deve esquecer, jamais, da capacidade de penetração, até latitudes muito baixas, da massa polar atlântica, nem também do papel representado pelos vales dos rios Paraná, Paraguai e Uruguai, no fenômeno da "friagem" da Amazônia. Suas calhas, que se alinham, "grosso modo", no sentido dos meridianos, funcionam como "corredores" para as trocas de energia entre as massas polares, tropicais e equatoriais, facilitando, assim, a ocorrência daquele fenômeno, típico dos invernos mais rigorosos.

Isso para não falar da estabilidade atmosférica, e consequente estiagem, que a massa polar "velha" (tropicalizada) promove sobre vasta porção do território nacional, no decorrer de certas primaveras austrais; ou, ainda, do papel exercido pela massa equatorial continental, e por seu "canal de umidade" que, rumo ao centro-sul do Brasil, distribui volumes de chuva além dos habitualmente esperados, cujos impactos costumam ser de grande monta.

Finalizando minhas considerações a respeito dos estudos geográficos do clima no Brasil e na Itália, que- ro externar minha crença nos avanços da Climatologia Geográfica Brasileira, que muito provavelmente vão continuar a ocorrer, pois os recursos hoje disponíveis são infinitamente superiores aos de outrora. Quanto à Itália, eu aposto positivamente na Profa. Dra. Simona Fratianni, da Universidade de Turim, que desde o ano de 2006 vem lidando com as variações do ritmo climático no Piemonte e suas implicações nos esportes de inverno e na produção vitivinícola no "terroir" do Barolo, dentre outras questões climáticas importantes, todas elas abrangentes e muito atuais.

\section{Agradecimento}

Agradeço a oportunidade que me foi oferecida pelo Prof. Dr. Cássio Arthur Wollmann para participar deste número comemorativo da Revista Ciência e Natura.

\section{Referências}

AOUAD, M.S. Tentativa de classificação climática para o estado da Bahia (uma análise quantitativa dos atributos locais associada à análise qualitativa do processo genético). 1978. 64f. Tese (Doutorado) FFLCH, USP, São Paulo, 1978.

BALDACCI, O. Nuove interpretazioni climatologiche. Cultura e Scuola, Roma, v.I, n.1, p.182-185, 1961.

BALDACCI, O. La climatologia geografica. Cultura e Scuola, Roma, v.XXV, n.100, p.190-199, 1986.

BIANCOTTI, A. Macaronesia: uomo, ambiente, spazio e territorio nelle isole dell' Atlantico orientale. Milano: World in Progress/BEM, 2001, 183p.

BOIN, M.N. Chuvas e erosões no oeste paulista: uma análise climatológica aplicada. 2000. 264f. Tese (Doutorado) - IGCE, UNESP, Rio Claro, 2000.

BORGHI, S. Climatologia dinamica dei tipi di tempo sul Veneto. Venezia: Regione del Veneto / Dipartimento Foreste, 1983, 61p.

BORGHI, S. Tipi di tempo e distribuzione delle precipitazioni sulla montagna Veneta. Padova: Regione del Veneto / Dipartimento Foreste, 1987, 191p. (Quaderni di Ricerca, 10)

CANTÙ, V. I lineamenti essenziali della meteorologia geografica. Cultura e Scuola, Roma, v.XX, n.80, p.167-173, 1981.

CROWE, P.R. Wind and weather in equatorial zone. Trans. and Papers, Inst. of Brit. Geogr., n.17, p.21- 
76, 1951.

FERRAZ, J.S. Ligeiro esbôço de alguns aspectos fundamentais da climatologia do Estado de São Paulo. In: Congresso Brasileiro, 9, 1942, Rio de Janeiro, Anais ..., Rio de Janeiro, 1942, v.II, p.425439.

FLETCHER, R.D. The general circulation of the tropical and equatorial atmosphere. Journ. of Meteor., v.II, p.167-174, 1945.

FONZAR, B.C. Os principais campos de pressão da América do Sul e sua atuação na caracterização do clima dos cerrados (savanas) do Centro-Oeste do Brasil. 1990. 297f. Tese (Doutorado) - FFLCH, USP, São Paulo, 1990.

FRANÇA, A. Estudo sôbre a clima da bacia de São Paulo. São Paulo: FFCL/USP, 1946, 59p. (Geografia, 3)

FRATIANNI, S.; BIANCOTTI, A.; GIUFFRIDA, A. Clima e turismo marino: i tipi di tempo estivi delle stazioni meteorologiche tirreniche. Rivista di Meteorologia Aeronautica, Roma, v.66, n.2, p.31-39, 2006.

FRATIANNI, S.; ZAVATTINI, J.A. I tipi di tempo e la coltivazione vitivinicola in Piemonte: il terroir del Barolo. In: Convegno Internazionale Paesaggi, Terroirs e I Paesaggi del Vino, 3, 2006, Perugia, Atti ..., Perugia, Università degli Studi di Perugia / Associazione Italiana Sommeliers, 2006 , p.147-157.

FRATIANNI, S.; ZAVATTINI, J.A. Neige, tourisme et types de temps dans la Vallée de Susa (Alpes Cottienes, Italie). In: Colloque de 1'Association Internationale de Climatologie, 20, 2007, Tunis, Actes ..., Tunis, AIC, 2007, 1 CD-ROM.

FRATIANNI, S.; ZAVATTINI, J.A.. Il contributo della climatologia dinamica all'analisi nivometrica e risvolti turistici in Val di Susa. Memorie della Società Geografica Italiana, Roma, v.LXXXVII, n.2, p.319-332, 2009.

GHELARDONI, P. (Org.) Studi in Onore di Mario Pinna. Memorie della Società Geografica Italiana, Roma, v. LV, n.1-2, 1998, 654p.

GHELARDONI, P. (Org.) Per ricordare Mario Pinna. Memorie della Società Geografica Italiana, Roma, v.LXX, 2003, 388p.

LATINI, A. Analisi della distribuzione delle precipitazioni nevose sulle Alpi italiane in relazione ai tipi di tempo e alle correnti in quota. Rivista di Meteorologia Aeronautica, Roma, v.XLVII, n.1, p.27-37, 1987.

MENNELLA, C. Il Clima d'Italia. Napoli: Edart, 1967, $723 p$.

MONTEIRO, C.A.F. Da necessidade de um caráter genético à classificação climática (algumas considerações metodológicas a propósito do estudo do Brasil Meridional). Revista Geográfica, Rio de Janeiro, v.31, p.29-44, 1962.

MONTEIRO, C.A.F. Sobre a análise geográfica de seqüências de cartas de tempo (pequeno ensaio metodológico sobre o estudo do clima no escopo da Geografia). Revista Geográfica, Rio de Janeiro, v.32, p.169-179, 1963.

MONTEIRO, C.A.F. Sobre um índice de participação das massas de ar e suas possibilidades de aplicação à classificação climática. Revista Geográfica, Rio de Janeiro, v.33, p.59-69, 1964.

MONTEIRO, C.A.F. Clima. In: IBGE. Geografia do Brasil - Grande Região Sul, 2ed. Rio de Janeiro: IBGE, 1968, v.IV, tomo I, p.114-166.

MONTEIRO, C.A.F. A frente polar atlântica e as chuvas de inverno na fachada sul-oriental do Brasil (contribuição metodológica à análise rítmica dos tipos de tempo no Brasil). São Paulo: USP/IG, 1969, $68 \mathrm{p}$.

MONTEIRO, C.A.F. Análise Rítmica em Climatologia. São Paulo: USP/IG, 1971, 21p. (Climatologia, 1)

MONTEIRO, C.A.F. A dinâmica climática e as chuvas no estado de São Paulo: estudo geográfico sob forma de atlas. São Paulo: USP/IG, [1964]1973, $129 \mathrm{p}$.

MONTEIRO, C.A.F. Teoria e clima urbano. São Paulo: USP/IG, 1976, 181p.

MONTEIRO, C.A.F. A Geografia no Brasil (19341977): avaliação e tendências. São Paulo: USP/IG, 1980, 157p.

MONTEIRO, C.A.F. Clima e Excepcionalismo: conjecturas sobre o desempenho da atmosfera como fenômeno geográfico. Florianópolis: Editora da UFSC, 1991, 241p.

MONTEIRO, C.A.F. O Estudo Geográfico do Clima. Florianópolis: Editora da UFSC, 1999, 72p. (Cadernos Geográficos, 1) 
MONTEIRO, C.A.F. A dinâmica climática e as chuvas no estado de São Paulo. 1.ed. Rio Claro: UNESP / AGETEO, 2000. 1 CD-ROM.

MORI, A. Il Clima. In: L'Italia Fisica. Milano: Touring Club Italiano, 1957, p.21-63.

PÉDELABORDE, P. Introduction a l'étude scientifique du climat. Paris: C.D.U. 1954.

PÉDELABORDE, P. Le climat du Bassin Parisien (Essai d'une méthode rationnelle de Climatologie physique). Paris: Éditions M. Th. Génin, 1957, 539p. (116 planches).

PÉDELABORDE, P. Introduction a l'étude scientifique du climat. Paris: S.E.D.E.S., 1970, 246p.

PÉDELABORDE, P. Introduction a l'étude scientifique du climat. Paris: S.E.D.E.S., 1991, 352p.

PINNA, M. Climatologia Dinamica e Geografia. Bollettino della Società Geografica Italiana, Roma, v.XCII, p.143-152, 1955.

PINNA, M. Moderne vedute sulla circolazione generale dell'atmosfera. L'Universo, Roma, v.XXXVI, n.3, p.403-420, 1956.

PINNA, M. La climatologia come disciplina geografica. Cultura e Scuola, Roma, v.III, n.10, p.129-137, 1964.

PINNA, M. La distribuzione geografica della temperatura dell'aria in Italia. Cultura e Scuola, Roma, v.VIII, n.31, p.138-148, 1969.

PINNA, M. Le variazioni del clima in epoca storica e i loro effetti sulla vita e le attività umane: un tentativo di sintesi. Bollettino della Società Geografica Italiana, Roma, v.X, p.198-275, 1969.

PINNA, M. Contributo alla classificazione del clima d'Italia. Rivista Geografica Italiana, Firenze, v.LXXVII, n.2, p.129-152, 1970.

PINNA, M. Precipitazioni nevose e durata del manto nevoso in Italia. Cultura e Scuola, Roma, v.XIII, n.51, p.144-157, 1974.

PINNA, M. Climatologia. Torino: UTET, 1977, 442p.

PINNA, M. L'Atmosfera e Il Clima. Torino: UTET, 1978, 478p.

PINNA, M. La Storia del Clima: variazioni climatiche e rapporto clima-uomo in età postglaciale. Memorie della Società Geografica Italiana, Roma, v.XXXVI, 1984, 261p.

PINNA, M. Contributi di Climatologia. Memorie della Società Geografica Italiana, Roma, v.XXXIX, 1985, 279p.

PINNA, M. Il Soleggiamento in Italia: brevi note climatologiche. Cultura e Scuola, Roma, v.XXV, n.99, p.209-220, 1986.

PINNA, M. Ippocrate: fondatore della teoria dei climi. Rivista Geografica Italiana, Firenze, v.95, p.3-19, 1988.

PINNA, M. L'inquinamento atmosferico in Italia: note climatico-ecologiche. Bollettino della Società Geografica Italiana, Roma, v.XI, n.5, p.3-33, 1988.

PINNA, M. La Teoria dei Climi: una falsa dottrina che non muta da Ippocrate a Hegel. Memorie della Società Geografica Italiana, Roma, v.XLI, 1988, 395p.

PINNA, M. La Teoria dei Climi: una falsa dottrina che non muta da Ippocrate a Hegel. Cultura e Scuola, Roma, v.XXVIII, n.111, p.169-180, 1989.

PINNA, M. Contributo allo studio del potere refrigerante del vento nelle aree montane d'Italia. Bollettino della Società Geografica Italiana, Roma, v.XI, n.6, p.545-566, 1989.

PINNA, M. L'aumento della temperatura nel XXI secolo e la sua influenza sul livello dei mari. Cultura e Scuola, Roma, v.XXIX, n.116, p.162-173, 1990.

PINNA, M. Sui caratteri climatici dell'arcipelago toscano. Rivista Geografica Italiana, Firenze, v.98, p.303-344, 1991.

PINNA, M. Le Variazioni Recenti del Clima (18001990) e le Prospettive per il XXI Secolo. Memorie della Società Geografica Italiana, Roma, v.XLVI, 1991, 569p.

PINNA, M. La Geografia tra Cultura Scientifica e Cultura Umanistica: brevi annotazioni suggerite da una recente opera sulle catastrofi naturali. Bollettino della Società Geografica Italiana, Roma, v.XI, n.9, p.721-728, 1992.

PINNA, M. La Bioclimatologia Umana: lo sviluppo recente di um'antica disciplina. Rivista Geografica Italiana, Firenze, v.100, p.487-511, 1993. 
PINNA, M. Confort e Disagio Climatico in Italia: contributo di bioclimatologia. Rivista Geografica Italiana, Firenze, v.103, p.339-358, 1996.

PINNA, M. Le Variazioni del Clima: dall'ultima grande glaciazione alle prospettive per il XXI secolo. Milano: FrancoAngeli, 1996, 214p.

PINNA, M. La climatologia nella seconda metà del secolo XX: alcuni elementi per un riesame. Bollettino della Società Geografica Italiana, Roma, v.XII, n.3, p.229-253, 1998.

QUENEY, P. Les grands mouvements de l'atomosphère. La Météorologie, Paris, set.1954, p.195-207.

ROSSBY, C.G. et al. On the general circulation of the atmosphere in middle latitudes. Bull. Amer. Met. Society, vol.28, p.255-280, 1947.

ROSSBY, C.G. On the nature of the general circulation of the lower atmosphere. In: The atmosphere of earth and planets. Chicago: University of Chicago Press, 1949, p.16-48.

ROSSATO, M.S. Os Climas do Rio Grande do Sul: variabilidade, tendências e tipologia. 2011. $240 f$. Tese (Doutorado) - IG, UFRS, Porto Alegre, 2011.

SANT' ANNA NETO, J.L. Ritmo climático e a gênese das chuvas na zona costeira paulista. 1990. 156f. Dissertação (Mestrado) - FFLCH, USP, São Paulo, 1990.

SETTE, D.M. O holorritmo e as interações trópicoextratrópico na gênese do clima e as paisagens do Mato Grosso. 2000. 394f. Tese (Doutorado) FFLCH, USP, São Paulo, 2000.

SORRE, M. Les fondements biologiques de la géographie humaine. Paris, 1943.

SORRE, M. Fundamentos biológicos de la Geografía Humana. Barcelona: Editorial Juventud, 1955, 344p.

URBANI, M. Su una classificazione di tipi di tempo in Europa. Rivista di Meteorologia Aeronautica, Roma, v.XV, n.3-4, p.30-37, 1955.

URBANI, M.. Sulla ciclogenesi nel Mediterraneo durante l'inverno. Rivista di Meteorologia Aeronautica, Roma, v.XVI, n.1, p.3-9, 1956.

ZAVATINI, J.A. Variações do ritmo pluvial no oeste de São Paulo e norte do Paraná (eixo Araçatuba - Presidente Prudente - Londrina). 1983. 225 f.
Dissertação (Mestrado) - FFLCH, USP, São Paulo,1983.

ZAVATINI, J.A. A dinâmica atmosférica e a distribuição das chuvas no Mato Grosso do Sul. 1990. 223f. Tese (Doutorado) - FFLCH, USP, São Paulo, 1990.

ZAVATINI, J.A. O advento do enfoque dinâmico na climatologia brasileira - desenvolvimento, progresso e perspectivas. In: Simpósio Brasileiro de Climatologia Geográfica, 1, 1992, Rio Claro. Resumos ..., Rio Claro, IGCE / UNESP, 1992, p. 86.

ZAVATINI, J.A. A climatologia brasileira, o enfoque dinâmico e a noção de ritmo climático - desenvolvimento, progresso e perspectivas. Boletim Climatológico, Presidente Prudente, v.1, n.2, p.11-20, 1996.

ZAVATINI, J.A. A climatologia geográfica brasileira, o enfoque dinâmico e a noção de ritmo climático. Revista Geografia, Rio Claro, v.23, p.5-24, 1998.

ZAVATINI, J.A. Desenvolvimento e perspectivas da Climatologia Geográfica no Brasil: o enfoque dinâmico, a noção de ritmo climático e as mudanças climáticas. In: SANT'ANNA NETO, J.L.; ZAVATTINI, J.A. (Orgs.). Variabilidade e Mudanças Climáticas. Maringá: EDUEM, 2000, p.225-251.

ZAVATTINI, J.A. O paradigma da análise rítmica e a climatologia geográfica brasileira. Revista Geografia, Rio Claro, v.25, p.25-43, 2000.

ZAVATTINI, J.A. O Paradigma do Ritmo na Climatologia Geográfica Brasileira (Teses e dissertações dos programas paulistas de pósgraduação - 1971-2000). 2001. 430f. Tese (Livredocência). IGCE, UNESP, Rio Claro, 2002.

ZAVATTINI, J.A. O tempo e o espaço nos estudos do ritmo do clima no Brasil. Revista Geografia, Rio Claro, v.27, p.101-131, 2002.

ZAVATTINI, J.A. A produção brasileira em climatologia: o tempo e o espaço nos estudos do ritmo climático. Revista Terra Livre, São Paulo, v.1, p.65-100, 2003.

ZAVATTINI, J.A. Estudos do Clima no Brasil. Campinas: Alínea, 2004, 398p.

ZAVATTINI, J.A. Les études du rythme climatique du Brésil au cours de la période 1971-2000. In: Colloque de 1'Association Internationale de Climatologie, 18, 2005, Gênes, Actes ..., Gênes, AIC, 
2005, p.317-320.

ZAVATTINI, J.A. As chuvas e as massas de ar no estado de Mato Grosso do Sul: estudo geográfico com vista à regionalização climática. 1.ed. São Paulo: Cultura Acadêmica, 2009, 214p. Disponível em: http://www.culturaacademica.com.br/catalogodetalhe.asp?ctl_id=42. Acesso em: 12 dez. 2013.

ZAVATTINI, J.A.; BOIN, M.N. Climatologia

Geográfica: teoria e prática de pesquisa. Campinas: Alínea, 2013, 150p. 